\section{PLENARY SESSION I}

P1 DETERMINANTS OF DEATH AND MAJOR COMPLICATIONS OF PREMATURITY IN A NATIONAL COHORT OF INFANTS BORN BEFORE 26 WEEKS' GESTATION

Costeloe KL and Hennessy E, for the EPICure Investigators Group.

St Bartholomew's and the Royal London School of Medicine and Dentistry, Queen Mary \& Westfield College, University of London

Funded by Serono Laboratories (UK) Ltd

Background: The EPICure study collected details of all births in the UK and Ireland $<26$ weeks gestational age (GA) between 1/3 and 31/12/1995.

Aim: To study determinants of death and of major complications of prematurity in this population.

Methods: Independent effects of maternal, obstetric and early neonatal factors were investigated using logistic regression. Outcomes examined were death, parenchymal cysts and/or hydrocephalus (PVL/HC), $\mathrm{O}_{2}$ dependency at 40 weeks $\left(\mathrm{O}_{2} 40\right)$ and treated retinopathy of prematurity $\left(\mathrm{R}_{x} \mathrm{ROP}\right)$. The effect of place of birth upon survival was examined by dividing hospitals $(n=276)$ into quintiles by numbers of births and admissions.

Results: After adjustment for postnatal factors gestation and birthweight were not predictive of death, $40 \%$ of babies were hypothermic at admission. Place of birth had no effect on survival. Of 811 admissions $61.3 \%$ died. Of the survivors $16.6 \%$ had $\mathrm{PVL} / \mathrm{HC}, 51.3 \%$ had $\mathrm{O}_{2} 40$ and $14.6 \%$ had $\mathrm{R}_{\mathrm{x}} \mathrm{ROP}$.

\begin{tabular}{lcccc}
\hline \multicolumn{1}{c}{ Predictive factors } & Death & $\mathrm{PVL} / \mathrm{HC}$ & $\mathrm{O}_{2} 40$ & $\mathrm{R}_{\mathrm{x}} \mathrm{ROP}$ \\
\hline Male & $\mathrm{p}<0.05$ & & $\mathrm{p}<0.001$ & \\
Lower GA & $\mathrm{p}<0.05$ & $\begin{array}{l}\mathrm{p}<0.001 \\
\mathrm{p}<0.05\end{array}$ & $\mathrm{p}<0.05$ & $\mathrm{p}<0.05$ \\
$\begin{array}{l}\text { No antenatal steroid } \\
\text { Tocolysis }\end{array}$ & & & & \\
Not Afro-Caribbean & $\mathrm{p}<0.05$ & & $\mathrm{p}<0.05$ \\
HR $<100$ at 5 mins. & $\mathrm{p}<0.05$ & & $\mathrm{p}<0.05$ & \\
$\begin{array}{l}\text { Temperature }<35^{\circ} \mathrm{C} \\
\text { High CRIB score }\end{array}$ & $\mathrm{p}<0.001$ & $\mathrm{p}<0.05$ & $\mathrm{p}<0.05$ & \\
$\begin{array}{l}\text { Postnatal transfer } \\
\text { Surfactant }\end{array}$ & & & $\mathrm{p}<0.001$ & \\
\hline
\end{tabular}

Conclusion: Early clinical condition is highly predictive of death and severe chronic lung disease in these babies. Strategies for improved care immediately after birth may improve outcomes. In this non-centralised service there is no effect of place of birth upon survival. The role of surfactant warrants further consideration.

\section{P2 THE INFLUENCE OF BREASTFEEDING AND SIZE FOR} GESTATIONAL AGE ON NEONATAL METABOLIC ADAPTATION

de Rooy LJ, Hawdon JM. The Neonatal Unit, University College London Hospitals, London, UK

Many clinical guidelines recommend regular blood glucose monitoring and routine formula supplementation of breast feeds in both small and large for gestational age (SGA and LGA) neonates. This practice does not take into account the provision of alternative cerebral fuels e.g. ketone bodies.

57 SGA (<2nd centile)and 23 LGA (>98th centile ) were studied. There was full support of breastfeeding and close clinical observation. Prefeed blood glucose (BG) and ketone body (KB) concentrations were measured in the first 7 postnatal days and values compared with those previously described for healthy, appropriate for gestational age (AGA) neonates. ${ }^{1}$

$17.5 \%$ SGA and $65 \%$ LGA babies were exclusively breastfed $(p=0.0002)$. The mean of each baby's BG during the study period did not differ (SGA 2.75 $\mathrm{mmol} / \mathrm{l} \mathrm{vs}$. LGA $2.77 \mathrm{mmol} / \mathrm{l})$, but SGA babies were more likely to have a blood glucose of $<2.00$ on 2 or more occasions (SGA $30 \%$, LGA $13 \%, p=0.04$ ). More SGA than LGA babies received IVI dextrose for hypoglycaemia alone (SGA $9 \%$, LGA $4 \%, p=N S$ ). Both groups had a peak KB comparable to those described for healthy AGA neonates (SGA $=0.379 \mathrm{mmol} / \mathrm{l}, \mathrm{LGA}=0.563 \mathrm{mmol} /$ I, $\mathrm{p}=\mathrm{NS}$ ) at which time $\mathrm{BG}$ was $2.70 \mathrm{mmol} / \mathrm{l}$ for $\mathrm{SGA}$ and $2.90 \mathrm{mmol} / \mathrm{l}$ for LGA babies. Multiple regression analysis demonstrated that volume of formula milk was negatively related to peak KB concentration $(p=0.0002)$, independent of size for gestational age and BG.

Neonatal ability to generate ketone bodies when BG is low depends more upon successful breastfeeding than upon size for gestational age, and is inhibited by early formula milk intake. These data suggest that routine BG monitoring of LGA infants is not necessary and routine formula milk supplementation of SGA and LGA babies should not be recommended.

${ }^{1}$ Hawdon et al. Arch Dis Child 1992;67:357-65.

\section{P3 BARKER OR BURGER? THE NEWCASTLE THOUSAND} FAMILIES AT FIFTY

Craft AW, Lamont D, Parker L. Department of Child Health, University of Newcastle upon Tyne

The 1142 babies born in Newcastle in May and June 1947 were recruited into a prospective cohort study - the Newcastle Thousand Families Study. They were followed up at the age of 50 years to determine the relative contributions of foetal/infant, childhood and adult factors to their current health.

Of the 967 children followed up to the end of the first year, 832 were traced and $574(69 \%)$ completed a postal questionnaire detailing past and present health and lifestyle. $412(49 \%)$ also underwent a health check consisting of anthropometric examination, ECG, blood lipids, cholesterol and a glucose tolerance test. Carotid artery intima media thickness (CAIMT), a marker of coronary vascular disease, was measured using B mode ultrasound scan. The relative contributions of foetal/infant, childhood and adult lifestyle factors to the development of cardiovascular disease and the central metabolic syndrome (CMS) were assessed using conceptual frameworks and multiple regression.

Socioeconomic position (SEP) at birth and birthweight were negatively correlated with CAIMT. Early life variables accounted for $2 \%$ of variance in CAIMT in both men and women. Adult socioeconomic position and lifestyle accounted for $3 \%$ of variance in men and $8 \%$ in women whilst biological risk markers in adulthood e.g. cholesterol were responsible for $10 \%$ of variation in men and $5 \%$ in women.

Birthweight and SEP accounted for 2 - 3\% of variation in CMS whilst adult SEP accounted for $9-12 \%$.

It is concluded that childhood and adult lifestyle have a greater influence on adult health then characteristics at birth.

\section{P4 INFLUENCE OF CHILDHOOD UNDER- AND OVER-WEIGHT ON ADULT HEALTH}

Wright CM, Parker L, Lamont D, Craft A. Department of Child Health, University of Newcastle upon Tyne

We have followed up 428 (46\%) members of the Thousand Families cohort at the age of 50 , who also had measurements at age 9 , to explore the association between adult and child BMI and a range of risk factors for adult ill health. Risk factors measured were: blood pressure and carotid artery intima-media thickness (IMT); total, LDL and HDL cholesterol; tryglycerides, fasting insulin and 2 hour glucose. Forty six study members $(11 \%)$ had been above the UK 1990 85th percentile at the age of nine and 18 of these $(39 \%)$ were obese $(\mathrm{BMl}>30)$ at age 50 . In total, however, $70(15 \%)$ were obese at age 50 and of these $3 / 4$ had been below the 85th percentile at age 9 .

$\mathrm{BMI}$ at age 9 showed little correlation with adult risk factors, while BMl at age 50 was highly positively correlated. However when adjusted for adult BMI using multiple regression, a consistent inverse association was found between BMl aged 9 and all the above risk factors, which was statistically significant $(P<0.05)$ for triglycerides, fasting insulin and 2 hour glucose in both sexes and for total cholesterol, diastolic and systolic blood pressure in women.

While childhood overweight was associated with higher rates of adult obesity, this was associated with a slightly lower risk profile than adult onset obesity. Adults who had been underweight as children generally showed the worst adult risk profile. 


\section{PLENARY SESSION II}

\section{P5 THE RISK OF SECOND PRIMARY TUMOURS IN SURVIVORS OF CHILDHOOD CANCER IN BRITAIN}

Jenkinson HC, Hawkins MM. Department of Public Health and Epidemiology, University of Birmingham, Birmingham B15 2TT

Second primary tumours (SPT) are one of the late sequelae faced by the increasing population of survivors of childhood cancer. In this population based, retrospective cohort study we aim to assess the risks of developing an SPT in 16,541 3-year survivors of childhood cancer diagnosed before 1988 in Britain.

We observed 278 SPT yielding an estimated relative risk (RR) of 6.6 and a cumulative risk by 20 years from 3 year survival of $5.3 \%$ (SE $0.4 \%$ ). 490 cases of genetic retinoblastoma had an overall RR of SPT of 17.4 and a RR of second bone cancer of 390. Exclusion of those diagnosed with retinoblastoma from the cohort resulted in an overall risk of SPT of 6.3 and a cumulative risk by 20 years from 3 year survival of $3.3 \%$ (SE $0.27 \%$ ). Analysis of the cohort excluding retinoblastoma demonstrated a decrease in risk of SPT with increasing length of follow up; RR 10.5 in the first decade from diagnosis falling to 3.1 in the fourth. Development of SPT was associated with treatment received (both radiotherapy and chemotherapy) and younger age at diagnosis (under 5 years). A striking increase was observed in the incidence of second myeloid leukaemia analysed by era of diagnosis; RR of $4.5,11.4$ and 69.9 observed in cases treated in 1960s, 70s and 80s respectively.

The risks of developing an SPT were comparable with other population based studies but considerably less than those arising from large centre based studies. These results demonstrate the need for continuing investigation of SPT risks in the decades following treatment of childhood cancer in order to guide long term clinical surveillance and facilitate the planning of future treatment protocols.

P6 RESULTS OF THE FIRST PROSPECTIVE SURVEY OF THE INCIDENCE, PRESENTATION AND MANAGEMENT OF INFLAMMATORY BOWEL DISEASE IN THE UNITED KINGDOM AND REPUBLIC OF IRELAND

Sawczenko A, Sandhu BK (on behalf of the BSPGN IBD group). Institute of Child Health, Bristol, UK

Introduction: Retrospective surveys have suggested that the incidence of Inflammatory Bowel Disease (IBD), Crohn's Disease (CD), Ulcerative Colitis (UC) and Indeterminate Colitis (IC), may be increasing.

Methods: From June 1998 until June 1999 all doctors that notify to the British Paediatric Surveillance Unit (BPSU) were asked to report new cases of IBD via their monthly orange carda. A detailed questionnaire regarding presentation, diagnostic investigation and initial management was sent to those that notified cases.

Results: $91 \%$ of doctors consistently returned their "orange cards" each month giving a minimum incidence of IBD amongst children aged $<16$ years of 4.7 / 100,000 / year. 325 clinicians made reports, but of these 252 saw only 1 or 2 new cases a year. Most children were seen by 2 or more clinicians. Overal $72 \%$ were seen by Paediatric Gastroenterologists, $10 \%$ by Adult Gastroenterologists and $9 \%$ by Adult Surgeons. $60 \%$ of cases were CD, $26 \%$ UC and $13 \%$ IC. CD patients were predominately male $(62 \%)$, but there was an equal sex distribution in the UC and IC groups. The mean age at diagnosis was 11.9 years, with $3 \%<5$ years. The median delay from onset of symptoms to diagnosis was 5 months, but $20 \%$ had had symptoms for $>12$ months. $10 \%$ of children had parents that came from an Ethnic Minority $(7 \%$ Asian, 3\% Afro-Caribbean). Asian children were more likely to have colitis. Systemic steroids were the initial treatment of choice in $48 \%$ of CD, $71 \%$ of UC and $54 \%$ of IC cases. $47 \%$ CD cases and $19 \%$ of IC cases were treated with diet (polymeric > elemental). Children seen by Paediatric Gastroenterologists were more likely to receive dietary therapy.

Conclusions: This is the first prospective epidemiological study of IBD in the United Kingdom and Republic of Ireland. The minimum incidence of IBD in children aged < 16 years during 1998/9 was 4.7 / 100,000 / year and is consistent with retrospective studies suggesting that there has been an increased incidence over the last decade. Currently there are variations in the initia management and treatment of IBD, with room for greater standardisation and thus optimisation of care.

\section{P7 CONGENITAL BRACHIAL PALSY (CBP) - INCIDENCE AND} AETIOLOGY

Evans-Jones LG, Kay SP, Ward A, Weindling AM. Countess of Chester Hospital, St James' University Hospital, Liverpool Women's Hospital

Introduction: CBP is generally believed to result from an injury at birth to part of, or all, the brachial plexus causing a flaccid paresis of, usually, one arm the commonest type being Erb's palsy. There is a suggestion that it may rarely occur spontaneously. The development of new surgical techniques and an increase in litigation has highlighted the need for accurate data on its incidence and aetiology. (The natural history is the subject of a future report).
Aims:

1. To calculate the current incidence of $\mathrm{CBP}$ in the United Kingdom and Republic of Ireland

2. To study its aetiology

Methods: From the $1^{\text {st }}$ April 1998 to the $31^{\text {st }}$ March 1999 active surveillance for CBP was undertaken through the B.P.S.U. Complementary data sources included reports from orthopaedic and plastic surgeons.

Results: A response rate of 0.91 was achieved with 332 cases confirmed, giving an incidence of 0.43 per 1000 live births. The table below gives a breakdown of mode of delivery:-

\begin{tabular}{|lrr|} 
& No & $\%$ \\
Normal Vertex & 186 & 56 \\
Ventouse & 91 & 27 \\
Forceps & 49 & 15 \\
Breech & 9 & 3 \\
Caesarean Section & 6 & 2 \\
\hline
\end{tabular}

Shoulder dystocia was present in $212(64 \%), 178(54 \%)$ infants were macrosomic, and $26(8 \%)$ suffered fractures or dislocation. In the majority (94\%) roots $\mathrm{C} 5,6$ and 7 were affected.

Conclusion: With no previous data for comparison, we cannot conclude that the incidence of CBP has changed in recent years, but it is unlikely to have fallen. In 21 cases (6\%) there was no evidence of injury.

P8 EFFICACY OF BOTULINUM TOXIN TYPE A TREATMENT IN LOWER LIMB SPASTICITY IN CHILDHOOD CEREBRAL PALSY: A RANDOMISED DOUBLE BLIND PLACEBO CONTROLLED TRIAL

Ubhi BS, Bhakta BB, Ives H and Roussounis SH. St James's University Hospital, Leeds, England

Aim: To measure the functional effect of Botulinum Toxin A in the treatment of lower limb spasticity in childhood cerebral palsy (CP).

Method: This is a randomised double blind parallel study comparing intramuscular Botulinum Toxin type A (BT-A) with placebo in spastic CP. All subjects (mean age 6-7 years; range 2 to 16 ) recruited were ambulant with spastic diplegia $(n=28)$ or hemiplegic $(n=12)$ CP causing dynamic equinus deformity with inability to achieve heel strike when walking. Five outcome measures were used: video gait analysis(VGA), gross motor function measure (GMFM), goniometry, functional mobility questionnaire (FMQ) and physiological cost index (PCI). In addition, parent and physician's rating of change were documented. Measurements were performed 2 weeks prior to injection, on the day of injection and at 2,6 and 12 weeks post injection. BT-A (Dysport) or placebo was injected into the gastrocnemius and soleus muscles at a dose of 25 mouse units per $\mathrm{kg}$.

Result: 22 patients received BT-A, 18 received placebo. VGA showed statistically significant improvements in walking pattern at all time points post injection in children receiving BT-A $(p<=0.001)$. Significant improvements (FMQ) in standinga $(\mathrm{p}=0.04)$, improved walking patterna $(\mathrm{p}=0.03)$ and walking unaided with splintsa $(p=0.02)$ were also found. GMFM demonstrated positive trends in favour of BT-A. Parents' rated significant improvement in children receiving $B T-A\left(p<0.001, X^{2}=10.62\right)$. The physician ratings similarly showed significant improvement $\left(p<0.001, X^{2}=17.03\right)$

Conclusion: The study shows that BT-A is effective in improving walking ability in children with lower limb spasticity due to hemiplegic or spastic diplegic $\mathrm{CP}$ 


\section{PLENARY SESSION III}

P9 SUBDURAL HAEMATOMA/EFFUSION (SDH/E) IN INFANCY REPORT OF A NATIONAL EPIDEMIOLOGICAL STUDY IN CONJUNCTION WITH THE BPSU

\author{
Hobbs C, Childs A, Wynne J, Seal A, Livingstone J. Departments of \\ Community Paediatrics and Paediatric Neurology, St James' University \\ Hospital \& Clarendon Wing, Leeds General Infirmary, Leeds
}

Subdural haematoma may present difficulties in diagnosis and management.

Aims: to study the epidemiology, causes, clinical features, investigation, management, and outcome at 6 months of SDH/E in 0-2 year infants diagnosed by $\mathrm{CT} / \mathrm{MRI} / \mathrm{US}$ scan or post mortem.

Methods: 12-month notification by Paediatricians, Forensic Pathologists Neurosurgeons via BPSU. Office of National Statistics made additional notification of deaths. Clinicians completed initial and 6 month follow up questionnaires.

Results: 181 infants $(118 \mathrm{~m}, 63 \mathrm{f})$ age $0-82$, mean 17.5 weeks fulfilled criteria. Rate (0-2y) for UK and Republic of Ireland $=10.64 / 100,000$ children aged 0 2. 30 infants died ( 1 accident, 7 birth trauma, 15 NAl, 3 disease, 1 unknown, 3 awaiting information). Predominant reported cause of SDH was trauma in 114, (accident in 7, NAI in 92, birth in 15). Other injuries included bruises in 64 , fractures (total 177) in 51, retinal haemorrhage in 60 and brain parenchymal injury in 72 infants.

Other causes included meningitis (SDE) in 20, clotting disorder in 3 , and other causes in 6 . In 36 cases there was no report, no cause or $>1$ cause identified. There were fewer of 5 key medical/social investigations (CT/MRI, ophthalmic examination, clotting studies, skeletal survey, child protection investigation) performed for these unclear diagnostic groups when compared with NAI group (respective means of 2.8, 3.7, 3.1 for unclear groups $\vee 4.6$ for NAl group).

Conclusions: $\mathrm{SDH}$ is a marker for major trauma in infancy. SDE usually follows meningitis (pneumococcal and meningococcal). Outside the neonatal period SDH is usually caused by NAI. SDH/E is associated with significant mortality and morbidity. Accurate diagnosis requires detailed and comprehensive medical, radiological, social and child protection investigation Management and outcome is reported elsewhere.

\section{P10 AT WHAT AGE SHOULD ROUTINE SCREENING START IN CHILDREN AT RISK OF FAMILIAL ADENOMATOUS POLYPOSIS?}

Hyer $\mathrm{W}^{\star}$, Neale $\mathrm{K}^{\star}$, Fell $\mathrm{JM}^{\star \star}$, Phillips RK.* ${ }^{\star}$ St Mark's Polyposis Registry, St Mark's Hospital, Middlesex ${ }^{* *}$ Department of Paediatric Gastroenterology, Chelsea and Westminster Hospital

Familial adenomatous polyposis (FAP) is an autosomal dominant premalignant condition which does not usually require treatment before adult life. One determinant of malignant risk is polyp density (100's -1000's). The optimal timing of screening by DNA testing or sigmoidoscopy is uncertain - ethical issues arise from early (pre-adolescent) diagnosis. Our protocol is to start screening at an age when the child can contribute to an informed decision (age 11-16 years); this study aimed to assess whether this approach has been appropriate in preventing malignancy in FAP affected children.

Method: To review the findings at screening sigmoidoscopy of 264 children on the St Mark's polyposis register aged 11-16 years with a first degree relative with FAP between 1949 and 1999

Results: 118/264 children have ultimately been diagnosed with FAP by sigmoidoscopy or DNA studies. Of these 118 patients, at endoscopy (median age 14) the number of cases (\%) with different polyp numbers were as follows: - No polyps 36 (30); approx $1-10$ polyps 56 (44); approx $11-20$ polyps 14 (12), 20-50 polyps 6 (5); $>50$ polyps 1 (1). Number not recorded 9 (8).

- There were no recorded malignancies in this cohort age $<16$ years.

Conclusion: At routine screening, the majority of children had low numbers of polyps. To date, this study represents the largest UK series of children and does not find evidence to support routine genotyping or sigmoidoscopy before age 14 years in children from families with FAP. Testing for FAP in children before this age should be done only where there is a clear justification.

P11 AUXILIARY LIVER TRANSPLANTATION FOR ACUTE HEPATIC FAILURE IN CHILDREN

A Dhawan ${ }^{1}, \mathrm{P}$ Muiesan $^{2}$, AJ Baker ${ }^{1}, \mathrm{H}$ Vilca Melendez ${ }^{2}$, G Mieli-Vergani ${ }^{1}$ ND Heaton ${ }^{2}$, M Rela $^{2}$. Departments of Child Health ${ }^{1}$ and Liver Transplantation ${ }^{2}$, King's College Hospital, London SE5 9RY

Auxiliary liver transplantation (APOLT) holds the potential advantage of stopping immunosuppression over conventional orthotopic liver transplantation for acute liver failure in children, but experience with the technique is limited. We describe our experience in 10 children (6 male, mean age 9 years, range 2.316 ) with acute liver failure (cryptogenic 6 , autoimmune 1 , mushroom poisoning 1 , paracetamol overdose 1, Wilson's disease) who fulfilled criteria for emergency transplantation. Average time from listing to transplantation was 1.5 days (1-4). Post-transplant, the INR and AST fell progressively in 8 children, with mean values at day seven of $1.16(0.9-1.4)$ and $48.6 \mathrm{IU} / \mathrm{I}(33-105)$ respec- tively. Two children died, 1 and 3 weeks after transplantation of primary graft dysfunction and candida biliary sepsis respectively. The other 8 children were discharged from hospital after an average period of 27 days (10-58) and are alive at a mean follow up of 28 months (range 7-64). 6 patients have a follow up greater than 12 months. The immunosuppression was tapered once the differential native liver DISIDA excretion was at least $50 \%$ and histologic regeneration of the native liver was documented on liver biopsy. The native liver has regenerated in 6 children, 4 of whom have stopped immunosuppression while 2 are on a tapering dose Two children have shown only minimal regeneration and remain on standard immunosuppression.

Conclusions: APOLT in children with acute liver failure is feasible, and allows withdrawal of immunosuppression in some patients.

P12 ALL IS GOLD, IS IT? DIFFERENCES BETWEEN ABSTRACTS OF RANDOMISED CONTROLLED TRIALS IN NEONATES SUBMITTED TO THE CONFERENCE AND THEIR FINAL PUBLICATION IMPLICATIONS FOR META-ANALYSIS

Rajneesh Walia, Arne Ohlsson. University of Toronto, Ontario, Canada

Objective: To study the differences between abstracts of randomised controlled trials (RCTs) in neonates submitted to the American Pediatric Society/ Society for Pediatric Research annual conference and their subsequent publication in peer-reviewed journal.

Methods: All RCT involving neonates submitted in 1993 and 1994 were identified by hand searching by each of the two authors. Medline, Embase, Cochrane Library and personal files were searched to identify their subsequent publication by author name(s) and subject titles by March 1999.

Results: During these two years, 1795 neonatal abstracts were submitted; 143 were RCTs of which 109 (76\%) were accepted for presentation. Seventy Six studies were subsequently fully published; $65 \%$ of these under different title, $59 \%$ with different numbers of enrolled neonates including $47 \%$ with increased numbers and $41 \%$ with increased numbers of authors.

Conclusion: Results of RCTs and high quality meta-analyses of such trials are generally accepted as the best available evidence. The identified differences in numbers of patients in abstracts and their full publications in this study has obvious implications for the accuracy of meta-analysis that include abstracts and the quality assessments of RCTs. These differences may indicate elements of bias/poor data quality control with regard to multiple looks at the data, changes in the definition of outcome, no preset sample size, and closure of patient recruitment at convenience.

\section{P13 NEONATAL LUNG DISEASE IS SIGNIFICANTLY IMPACTED BY} TNF- $\alpha-308$ POLYMORPHISM

Doulah MA, Simpson NAB, Ferriman EL, ReidJG, Rollason G, Dear PRF and Walker JJ. Academic Unit of Child Health and Obstetrics, University of Leeds, Leeds, Yorkshire

Introduction: Infants who develop chronic lung disease have significantly increased concentrations of TNF- $\alpha$ on days 2 and 3 of life. A polymorphism that directly affects the regulation of TNF- $\alpha$ is located at -308 nucleotides relative to the transcriptional start site of the gene. The two allelic forms referred to are known as $\mathrm{TNF}^{\star} 1$ and $\mathrm{TNF}^{\star} 2$.

Aims: To see if the TNF- $\alpha-308$ nucleotide polymorphism is a factor in the severity of neonatal lung disease.

Methods: The TNF- $\alpha-308$ genotype of 164 preterm babies with neonatal lung disease was determined from neonatal blood spots using PCR-RFLP. Statistical analysis was performed using non-parametric methods.

Results: Within the study population there was a decrease in the duration of lung disease as indicated by oxygen requirement, according to the TNF- genotype (figure 1). Homozygotes for $\mathrm{TNF}^{\star} 2$ had the lowest median oxygen days. There was no significant difference in the gestation, birthweight or use of antenatal steroids between the groups.

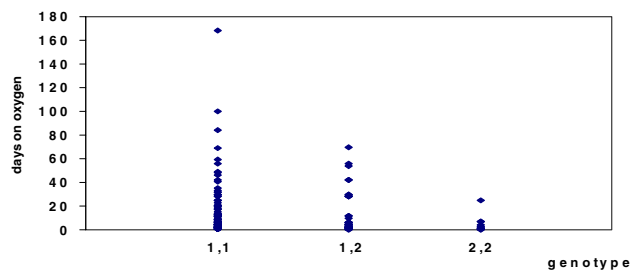

Median oxygen requirement by genotype was 6 days $(1,1), 3$ days $(1,2)$ and 2 days $(2,2)$. Using the Kruskal-Wallis test there was a significant difference in the medians between the three groups $(p=0.008)$.

Conclusion: The mean duration of lung disease as indicated by oxygen requirement is significantly associated with TNF- $\alpha-308$ genotype. This has important implications for the pathogenesis of respiratory distress syndrome and CLD. 


\section{PLENARY SESSION IV}

P14 NEURODEVELOPMENTAL OUTCOME OF MENINGOCOCCAL DISEASE OCCURRING IN CHILDREN UNDER 5 YEARS OF AGE

Fellick JM, Thomson APJ, Sills JA, Marzouk O, Hart CA, Cooke RWI. Institute of Child Health, Royal Liverpool Children's Hospital NHS Trust

Aims: To determine 10-year neurodevelopmental outcome in children less than 5 year of age at the time of meningococcal infection.

Methods: Case-controlled follow-up study.

Subjects: 102 survivors of meningococcal disease between 1988-1990 were identified. All subjects were less than 5 years of age at presentation Between 1998 and 199986 children (84\% of the cohort) were tested, as were 86 sex- and age-matched controls registered with the index case's GP

Outcome measures. Neurological examination including 6 neurological soft signs, Movement ABC test of motor skills and Wechsler Intelligence Scales for Children (WISC-3).

Results: One case has spastic quadriplegia and microcephaly. Gross neurological examination was normal in the other 85 cases and all of the controls. There was no significant difference in the neurological soft sign scores between cases and controls.

16 cases (18.6\%) and 4 controls $(4.7 \%)$ had scores on the movement $A B C$ indicative of a significant motor problem ( $p=0.004$, chi-square test).

The mean total IQ score was 92.5 in cases compared to 101.3 in controls (mean difference 8.8). After adjusting for socio-demographic variables this difference remained significant at 6.8 points $(95 \% \mathrm{Cl}=2.2-11.3, \mathrm{p}=0.004$, test for independent samples).

Conclusion: Although the majority of survivors of meningococcal disease from this cohort do not have major neurological deficits there is an increased risk of significant motor and cognitive impairment compared to the contro population.

\section{P15 OUTCOME OF INTESTINAL TRANSPLANTATION (ITX)}

Beath SV ${ }^{1}$ Brook GA ${ }^{1}$ Kelly DA ${ }^{1}$ McKiernan $\mathrm{PJ}^{1}$ Protheroe SP${ }^{1}$ Booth IW Murphy MS ${ }^{1}$ Mayer $A D^{2}$ Mirza $D^{2}$ Buckels $J A^{2}$ de Ville de Goyet $J^{1}$. The Children's Hospital', and The Queen Elizabeth Hospital', Birmingham, B4 $6 \mathrm{NH}$

Since 1993, 28 children were listed for ITx, 13 died on the waiting list, 12 have been transplanted and 3 are currently waiting. Data relating to recipient weight, time on waiting list, diagnosis, operation type and outcome of ITx are presented.

\begin{tabular}{|c|c|c|c|c|c|}
\hline $\begin{array}{c}\text { Case } \\
\text { no. }\end{array}$ & $\begin{array}{l}w t \\
k g\end{array}$ & $\begin{array}{l}\text { waiting } \\
\text { time } \\
\text { days }\end{array}$ & diagnosis & operation & $\begin{array}{l}\text { outcome, }()= \\
\text { follow up months }\end{array}$ \\
\hline 1 & 14 & 79 & short gut & whole CSBLTx & died PTLD (6) \\
\hline 2 & 13 & 180 & pseudo-obs & whole CSBLTx & died ARDS (1) \\
\hline 3 & 10 & 480 & MVID & isolated ITX & died CMV (9) \\
\hline 4 & 18 & 550 & Hirchspr. & isolated ITX & alive (33) \\
\hline 5 & 7.6 & 344 & MVID & whole CSBLTx & alive (19) \\
\hline 6 & 24 & 109 & pseudo-ob & whole CSBLTx & alive (18) \\
\hline 7 & 8 & 68 & short gut & reduced CSBLTx & alive (13) \\
\hline 8 & 8.5 & 144 & short gut & isolated ITx & died ARDS (1) \\
\hline 9 & 9.2 & 24 & short gut & whole CSBLTX & alive (12) \\
\hline 10 & 10.2 & 97 & short gut & reduced CSBLTX & alive (9) \\
\hline 11 & 7.3 & 36 & short gut & reduced CSBLTX & alive (7) \\
\hline 12 & 5.9 & 24 & short gut & reduced CSBLTX & died ARDS (1) \\
\hline
\end{tabular}

CSBLTX $=$ combined small bowel \& liver transplantation, $P T L D=$ post transplant lymphoproliferative disease, $A R D S=$ acute respiratory distress syndrome, MVID = Micro-villus Inclusion disease, Hirchspr = Hirchsprung's disease

Good intestinal function was achieved in nine children who became independent of PN by day 70 (mean 37 days). 3 children died in ITU of ARDS triggered by sepsis. Two children died after 6-9 months from opportunistic infections (PTLD and CMV). Because of the donor shortage we have accepted a size mismatch ratio of $3: 1$ in four patients by reducing the liver en bloc with small bowel graft. There are seven medium term survivors, all achieved independence from parental nutrition. Despite a median of three acute admissions per year for evaluation of fever all are currently well. We conclude that ITx is feasible even in small recipients, but it requires close follow up and community paediatric support.

\section{P16 LONG-TERM RENAL FUNCTION AFTER CARDIAC TRANSPLANTATION: THE INFLUENCE OF EARLY CYCLOSPORIN DOSAGE}

Hornung TS, de Goede CGEL, O'Brien C, Moghal NE, Dark JH, O'Sullivan JJ. Department of Paediatric Cardiology and Department of Cardiothoracic Surgery, Freeman Hospital, Newcastle upon Tyne
Background/Aims: Despite recognition of the nephrotoxicity of cyclosporin (CyA) therapy, there is little data on renal function in paediatric heart transplant recipients. We sought to document long-term renal function after heart transplant and to assess influence of early CyA levels.

Methods: We reviewed all children transplanted at our centre from June 1985 to August 1998 who survived $>6$ months $(n=54)$. Glomerular filtration rate (GFR) was estimated at 1,2, 4 and 8 years post-transplantation using the Schwartz formula. We analysed whether change in renal function correlated with mean trough CyA levels.

Results: Median age at transplantation was 4 years and median follow-up 5 years. Survival rates were $87 \% 1$ year and $80 \% 5$ year. Mean GFR pre-transplant was $79\left(19 \mathrm{ml} / \mathrm{min} / 1.73 \mathrm{~m}^{2}\right.$, partly reflecting low cardiac output and reduced renal perfusion. One year later, mean GFR was $72 \mathrm{ml} / \mathrm{min} / 1.73 \mathrm{~m}^{2}$ $(\mathrm{P}=0.05)$, and after 2 years $65 \mathrm{ml} / \mathrm{min} / 1.73 \mathrm{~m}^{2}(\mathrm{P}=0.03), 4$ years (35 patients) $60 \mathrm{ml} / \mathrm{min} / 1.73 \mathrm{~m}^{2}$ and 8 years (14 patients) $57 \mathrm{ml} / \mathrm{min} / 1.73 \mathrm{~m}^{2}$. CyA levels ove the first two months correlated with GFR change over the first year $(P=0.0007$, $r^{2}=0.21$ ). CyA levels over the next 10 months further correlate with GFR reduction over the second year $\left(P=0.03, r^{2}=0.13\right)$.

Conclusions: This study is important as it demonstrates for the first time that decline in renal function after heart transplantation is closely correlated with early CyA exposure. Early immunosuppressive regimes should therefore be individualised to allow the lowest CyA level that will prevent rejection. New immunosuppressive drugs may result in a better renal outlook for this group.

\section{P17 METABOLIC CONTROL AND QUALITY OF LIFE IN 2,101 ADOLESCENTS WITH DIABETES}

Hoey H.M.C. $V^{1}$, Mortensen $\mathrm{H}^{2}$, Robertson K.J $\mathrm{J}^{3}$, Swift $\mathrm{P}^{4}$, Greene S. $\mathrm{A}^{5}$ McGee $\mathrm{H}^{6}$, Fitzgerald $\mathrm{M}^{1}$, Hougaard $\mathrm{P}^{7}$, Lynggaard $\mathrm{H}^{7}$ for the Hvidøre Study Group on Childhood Diabetes. ${ }^{1}$ National Children's Hospital, Trinity College, Dublin; ${ }^{2}$ Glostrup University Hospital, Denmark; ${ }^{3}$ Royal Hospital for Sick Children Glasgow; ${ }^{4}$ Leicester Royal Infirmary; ${ }^{5}$ Ninewells Hospital, Dundee; ${ }^{6}$ Royal College of Surgeons Dublin; ${ }^{7}$ Novo Nordisk A/S, Denmark

Aims: A study involving 17 countries including Europe, Japan and North America was conducted to study the association between quality of life QOL) and metabolic control in adolescents with diabetes and their parents.

Methods: HbA1c was analysed centrally. Adolescent QOL was assessed by the Diabetes Quality of Life Questionnaire, and family burden by questionnaires to parents and health professionals. 2101 adolescents participated (boys 1085, girls 1016); medians: age 14.0 years (range $10-18$ years); diabetes duration 5 years (range $0-17$ years); $\mathrm{HbA} 1 \mathrm{c} 8.5 \%$ (4.8-17.4).

Results: Adolescents with lower HbA1c had a higher QOL $(p=0.01)$; and lower parental $(p=0.0001)$ and health professional assessment of burden $(p=0.0001)$. QOL was significantly higher for younger adolescents $(p=0.0001)$, and for boys than for girls. Parental burden was greater in the younger, and in boys of both age groups. QOL was unrelated to duration of diabetes $(p=0.33)$, although $\mathrm{HbA1c}$ rose with age. There was no significant relationship between number of insulin injections per day $(p=0.61)$ or use of premixed insulin ( $p=0.31$ ) with $\mathrm{QOL}$ for the adolescent or family burden $(p=0.61$ and 0.95$)$. Hypoglycaemia related to health professional burden $(p=0.006)$, but not to QOL of adolescent or parental burden. Body mass index (BMI) was strongly and inversely related to adolescent $Q O L(p=0.005)$, but not to family burden $(p=0.78)$.

Conclusions: Good HbA1c levels are associated with a better QOL for adolescents and a lesser-perceived burden by parents and professionals. $\mathrm{QOL}$ is unrelated to the number of insulin injections, use of premixed insulin, or to hypoglycaemia (except for health professional burden). Greater attention should be given to BMI as a source of QOL impairment.

\section{P18 THE ASSOCIATION BETWEEN DISEASE SEVERITY, CYTOKINES AND VIRUS GENOTYPE IN INFANTS WITH RESPIRATORY SYNCYTIAL VIRUS (RSV ) BRONCHIOLITIS}

Smyth R.L ${ }^{1}$, Mobbs $\mathrm{K}^{2}$ O'Hea $\mathrm{U}^{1}$, Ashby $\mathrm{D}^{3}$ and Hart $\mathrm{CA}^{2} .{ }^{1}$ Institute of Child Health, ${ }^{2}$ Dept of Medical Microbiology and Genito-Urinary Medicine, University of Liverpool ${ }^{3}$ Wolfson Institute of Preventive Medicine, Queen Mary and Westfield College, University of London

Background: There is considerable controversy about whether, in infants with RSV bronchiolitis, disease severity is determined by characteristics of the infecting virus, or by the host immunopathological response to the virus. IL- 8 is a chemokine associated with polymorphonuclear and eosinophil recruitment and although not investigated extensively in RSV bronchiolitis has been implicated in the immunopathology of asthma.

Objectives: To investigate the associations between disease severity, cytokine concentrations and virus genotype in a large epidemiological study of infants with RSV bronchiolitis.

Methods: 264 infants with confirmed RSV infection were recruited. Nasopharyngeal aspirates were obtained for virus genotyping and assays of cytokine mRNA. RSV NP- and G-genotyping was successfully performed by RT-PCR and restriction endonuclease digestion in 239/264. A semi-quantitative assay was used to estimate mRNA concentrations of IL- 8 relative to a 
constitutively expressed gene Hgprt in 166/264. Infants requiring oxygen or ventilation were classified as having severe disease.

Results: 93/166 infants in whom IL-8/Hgprt was measured had severe disease. A highly significant association was found between the amount of IL8/ Hgprt in the nasopharyngeal aspirate and the occurrence of severe disease. Odds ratio per unit increase of IL-8/Hgprt was 1.15 (95\% Cl 1.06,1.24), $\mathrm{P}=0.0004$. There was no association between virus genotype and either disease severity or amount of IL-8/Hgprt.

Conclusion: The strong, dose-related association between IL-8 in samples from the airways and disease severity and the lack of association with virus genotype, suggest that the clinical manifestations of RSV bronchiolitis are determined by the immunological response to RSV infection.

This study was supported by grants from the Foundation for the Study of Infant Deaths and RLCH Endowment Funds

\section{PLENARY SESSION V}

\section{P19 RANDOMISED COMPARISON OF EARLY NASAL CPAP WITH CONVENTIONAL VENTILATION IN THE TREATMENT OF} RESPIRATORY DISTRESS IN THE PRETERM NEWBORN

Tooley JR, Dyke MP. Department of Paediatrics, Norfolk and Norwich Hospital, Norwich, England

Objective: To evaluate whether very preterm babies can be extubated successfully to nasal CPAP within one hour of birth after receiving one dose of surfactant in the treatment of moderate severity respiratory distress syndrome (RDS).

Study design: 42 infants of 25 to $28^{+6}$ weeks gestation with mild to moderate RDS were intubated at birth and given one dose of surfactant (ALEC). They were then randomised within 1 hour of birth to either continue with conventional ventilation or to be extubated to nasal CPAP (after receiving a loading dose of caffeine)

Results: $8 / 21(38 \%)$ of babies randomised to CPAP did not require subsequent reventilation for RDS. (ventilation rates of $62 \%$ vs $100 \%, p=0.0022$ ). The smallest baby successfully extubated weighed 745 grams. There was no significant difference between the two groups in the number of babies that died or developed IVH, PIE or Chronic lung disease (CLD).

Conclusions: A significant number of very preterm babies with moderately severe RDS can be extubated to nasal CPAP after receiving only one dose of surfactant. Nasal CPAP is a potentially useful modality of respiratory support even in very premature infants. A larger study is required to establish whether important long term outcome measures, including incidence of CLD can be reduced through the early use of CPAP.

P20 MALIGNANT GERM CELL TUMOURS: CURE AT LEAST COST

Mann JR, ${ }^{1}$ Raafat F, ${ }^{1}$ Robinson $\mathrm{K},{ }^{2}$ Imeson $\mathrm{J},{ }^{2}$ Stiller $\mathrm{CA},{ }^{3}$ Gornall $\mathrm{P},{ }^{1}$ Sokal $\bar{M},{ }^{4}$ Gray $E,{ }^{5}$ McKeever $P,{ }^{6}$ Hale J, ${ }^{7}$ Bailey $S,{ }^{7}$ Oakhill $A^{8}$ on behalf of the UK Children's Cancer Study Group. ${ }^{1}$ Birmingham Children's Hospital, ${ }^{2}$ UKCCSG Data Centre Leicester, ${ }^{3}$ CCRG Oxford, ${ }^{4}$ City Hospital Nottingham, ${ }^{5}$ Medical School Aberdeen, ${ }^{6}$ University of Leicester, ${ }^{7}$ Institute of Child Health Newcastle-upon-Tyne, ${ }^{8}$ Royal Hospital for Sick Children Bristol

Background: Better chemotherapy has improved 5 year survival rates of British children with malignant extra-cranial germ cell tumours (MGCTs) from $64 \%, 40 \%$ and $6 \%$ for testicular, ovarian and non-gonadal sites respectively for cases diagnosed in $1962-66$ to $95 \%, 84 \%$ and $73 \%$ for $1984-1988$ cases. However, $45 \%$ of survivors of cisplatin-containing regimens had renal impairment and $10 \%$ were deaf.

Aims: The UKCCSG'S second study aimed to minimise toxicity while maintaining high cure rates.

Methods: Children aged 0-16 years with histology-reviewed MGCTs and no prior chemotherapy had standard investigations. Tumours were excised if feasible without major morbidity, otherwise biopsied. Stage I testicular and a few other Stage I cases were treated by surgery alone and then monitored clinically and by AFP levels. Recurrent Stage I and all other cases had 'JEB' chemotherapy: etoposide $120 \mathrm{mg} / \mathrm{m}^{2}$ Days $1-3$, carboplatin $600 \mathrm{mg} / \mathrm{m}^{2}$ Day 2 and bleomycin $15 \mathrm{mg} / \mathrm{m}^{2}$ Day 3 , courses being given every 3-4 weeks until remission, then 2 more courses. Residual tumour was excised.

Results: Between 1989 and 1997192 patients were registered, 3 excluded for no pathology review and 5 because they were given other chemotherapy. Forty-seven had only surgery and 137 had JEB. Overall 5 year survival in 184 cases was $93.2 \%(\mathrm{Cl} 87.9-96.3)$ by site: testis, vagina and uterus $100 \%$, ovary $92.3 \%$, sacrococcygeal area $87.6 \%$, thorax $83.1 \%$, other $87.5 \%$. JEB caused manageable non-fatal haematological toxicity but no significant renal or pulmonary toxicity and Grade 3 deafness in only one child. One girl died of acute myeloid leukaemia.

Conclusions: Conservative surgery and JEB chemotherapy produce acceptable toxicity and high cure rates.

P21 COST-BENEFIT FAILURE OF PROPHYLAXIS WITH PALIVIZUMAB (SYNAGIS) FOR RESPIRATORY SYNCYTIAL VIRUS INFECTION IN PREMATURE INFANTS

Buck JJ, Debenham P, Tasker RC. Department of Paediatrics, Box 116 University of Cambridge School of Clinical Medicine, Addenbrooke's Hospital, Hill's Road, Cambridge

The IMpact-RSV study group has concluded that monthly intramuscular Palivizumab (PZB or Synagis) is safe and effective for the prevention of serious RSV illness in premature children and those with BPD.

Aims: To determine whether the introduction of Palivizumab immunisation in the recommended at risk groups is cost beneficial in a defined geographical population.

Methods: A retrospective review of the patients under 24 months of age with RSV bronchiolitis admitted to Addenbrooke's Hospital during the winter 1998/9 was carried out. Calculations were made of potential cost benefits to the health authority had PZB immunisation been introduced to infants in the region born < 35 wks and $<6$ months age, or with BPD aged $<2$ yrs. 
Results: Seventy two from a population of $>9000$ Cambridge infants $<2$ yrs of age were admitted with RSV positive bronchiolitis between Oct 98 and March 99. The median age was 5.2 (IQR 1.9-8.0)months with a median duration of stay of 4.5 (IQR 3.0-6.8) days. Four patients were admitted to paediatric intensive care occupying a total of 10 days. There were no deaths. Only 5 of the $72(7 \%, 95 \% \mathrm{Cl} 1-13 \%)$ would have received PZB prophylaxis as per the published guidelines*. These 5 occupied a total of 29 inpatient days (none on $\mathrm{PICU}$ ) at a cost of $£ 7395$. In the region there were 51ex-premature infants $<6$ months of age and an additional 11 with BPD $>6$ months old. Had these infants all been immunised, each with 5 doses of PZB, this would have cost the local HA £131 440 and potentially prevented $3(1-5)$ admissions (NNT $17(11-36)^{\star}$ ). An estimated 17 beddays could have been saved (approx $50 \%$ reduction in stay for immunised infants) ${ }^{\star}$. The total excess cost to the HA would have been $>£ 100$ 000.*IMpact study data

Conclusions: The proposed targeted prophylaxis for RSV infection with Palivizumab could result in an inefficient use of limited HA resources.

${ }^{1}$ The IMpact-RSV study group. Palivizumab, a humanised respiratory syncytial virus monoclonal antibody, reduces hospitalisation from respiratory syncytial virus infection in high-risk infants. Pediatrics 1998;102:531-537.

P22 PARENTS' INTERPRETATION OF CHILDREN'S RESPIRATORY SYMPTOMS SHOWN ON VIDEO

Cane RS, McKenzie SA. Queen Elizabeth Children's Services, Royal London Hospital, London

Background: Reported wheeze is the cornerstone of asthma diagnosis. How well do parents recognise wheeze?

Aim: To compare parents and doctors interpretations of respiratory signs shown on video.

Method: Five clinicians were in full agreement about respiratory noises (wheeze, upper airway noise (UA)) recorded from 9 children on videos. Parents of children $<8$ years, using hospital services, were shown the video clips. The subject groups were parents of children with a) asthma or 'wheeze', b) other respiratory problems and c) no respiratory complaints. They were asked to name the sounds and their source. Responses were grouped correct, vague, don't know or incorrect and then compared to clinician's responses.

Results: 190 parents watched the videos. The overall correct identification of wheeze was $50 \%$ (95\% confidence interval $(\mathrm{Cl}) 44-56 \%$ ). For UA clips, this was $33 \%(\mathrm{Cl} 28$ 38\%). There were no differences between groups for correctly labelling wheeze and UA. For locating wheeze, the overall correct response was $83 \%(\mathrm{Cl} 79-87 \%)$. For UA clips this was $62 \%(\mathrm{Cl} 5768 \%)$.

Conclusion: Irrespective of group, agreement of parents and doctors for labelling sounds was about $50 \%$. Parents were more concordant with doctors in locating sounds. Parents and professionals do not use the same words for labelling the breathing sounds of children on videos. The validity of responses to questions about wheeze in epidemiology and clinical settings needs addressing and the value of videos as clinical tools needs to be assessed.

\section{PLENARY SESSION VI}

\section{P23 UK COLLABORATIVE ECMO TRIAL: FOLLOW-UP AT FOUR YEARS OF AGE}

Bennett CC. on behalf of the UK Collaborative ECMO Trial Group National Perinatal Epidemiology Unit, Oxford University

Background: The UK ECMO Trial showed that a policy of transfer for consideration for ECMO support reduced the risk of death in babies with acute respiratory failure when compared with conventional management $(30 / 93$ ECMO; 54/92 CM). This reduction in mortality did not appear to be at the expense of severe disability among survivors at age one year.

Aims: To describe the outcome of survivors at age four years

Methods: 93 of the 98 children available for follow-up were assessed by a single observer. Clinical information available on a further 2 children. Outcome categories were pre-defined.

Results: Cognitive abilities and neuromotor function was similar in both trial arms, but there was a higher level of respiratory and behavioural morbidity among survivors treated conventionally. Progressive sensori-neural hearing loss was found in both groups.

$\begin{array}{lcc}\text { Overall outcome at four years } & \text { ECMO (n=61) } & \text { CM }(\mathbf{n}=\mathbf{3 5}) \\ \text { Normal } & 12(20 \%) & 4(11 \%) \\ \text { Impairment } & 18(30 \%) & 9(26 \%) \\ \text { Mild disability } & 18(30 \%) & 12(34 \%) \\ \text { Moderate disability } & 9(15 \%) & 10(29 \%) \\ \text { Severe disability } & 3(5 \%) & 0(0 \%)\end{array}$

Conclusions: This study provides the first long-term morbidity data of a neonatal ECMO policy compared to contemporary conventional management. The improved survival is not offset by an increase in disability. These results continue to support UK ECMO Trial conclusions and favourably advocate the safety and efficacy of this intervention.

\section{P24 THE HYPERGLYCAEMIC EFFECTS OF HYDROCHLOROTHIAZIDE INVOLVE ACTIVATION OF POTASSIUM CHANNELS IN INSULIN-SECRETING CELLS}

${ }^{1}$ Barnes PD, ${ }^{1} \mathrm{O}$ 'Brien RE, ${ }^{1}$ Cosgrove KE, ${ }^{2}$ Abdel-Wahab YHA, ${ }^{2}$ Flatt PR, ${ }^{3}$ Aynsley-Green A, ${ }^{1}$ Dunne MJ. ${ }^{1}$ Department Biomedical Science, Sheffield University, Sheffield; ${ }^{2}$ Department Biomedical Science, Ulster University, Coleraine; ${ }^{3}$ The Institute of Child Health, London.

Thiazide diuretics are widely used to treat hypertension, but are also known to impair glucose tolerance and even induce diabetes in some patients. Additionally, thiazides are used in conjunction with diazoxide in the treatment of neonatal hyperinsulinism (HI). Since anecdotal evidence suggests that thiazides can improve the control of glycaemia in $\mathrm{HI}$ patients, we have examined the actions of the thiazide diuretic hydrochlorothiazide (HCT) on isolated insulin-secreting cells. Using the glucose-responsive $\beta$-cell line, BRIN-BD11 we found that HCT $(10-100 \mu \mathrm{M})$ inhibited both glucose $(15 \mathrm{mM}, \mathrm{n}=8)$ and tolbutamide-induced insulin secretion $(100 \mu \mathrm{M}, \mathrm{n}=8)$ in a similar manner to the $\mathrm{K}_{\mathrm{ATP}}$ channel agonist diazoxide $(10-100 \mu \mathrm{M}, \mathrm{n}=8)$. Surprisingly, at $1 \mu \mathrm{M}$ concentrations, HCT inhibited insulin release to near basal values, whilst diazoxide was without effect. Using the patch-clamp technique, HCT $(1 \mu \mathrm{M}-100 \mu \mathrm{M})$ was found: [1] to activate $\mathrm{K}_{\mathrm{ATP}}$ channels, and [2] to reverse both the ATP $(0.5 \mathrm{mM})$ - and tolbutamide $(100 \mu \mathrm{M})$-induced inhibition of $\mathrm{K}_{\text {ATP }}$ channels in either BRIN BD11 $\beta$-cells $(\mathrm{n}=12-38)$, or control human $\beta$-cell recordings $(\mathrm{n}=17)$. Since $\mathrm{HI}$ arises from defects in the regulation of $\mathrm{K}_{\mathrm{ATP}}$ channels in $\beta$ cells, we examined the effects of $\mathrm{HCT}$ on the large conductance $\mathrm{Ca}^{2+}$ - and voltage-activated $\mathrm{K}^{+}\left(\mathrm{K}_{\mathrm{Ca}}\right)$ channel in these cells. In 12 experiments using $\beta$ cells isolated from $\mathrm{HI}$ tissue post-operatively, $\mathrm{HCT}(1 \mu \mathrm{M}-100 \mu \mathrm{M})$ caused a marked augmentation of the $\mathrm{Ca}^{2+}$-dependent activation of $\mathrm{K}_{\mathrm{Ca}}$ channels. In summary, these data show that the thiazide diuretic HCT is an agonist of $\mathrm{K}_{\mathrm{ATP}}$ channels in control $\beta$-cells and that this is causally-related to the inhibition of insulin release. In $\beta$-cells that lack $\mathrm{K}_{\mathrm{ATP}}$ channels, $\mathrm{HCT}$ activated $\mathrm{K}_{\mathrm{Ca}}$ channels, and this may explain why thiazide diuretics have a beneficial effect on the control of glycaemia in patients with neonatal hypoglycaemia.

P25 FETAL CARRIAGE OF TNF*2 IS ASSOCIATED WITH PREMATURE MEMBRANE RUPTURE AND SUBSEQUENT PRETERM DELIVERY

Ferriman EL, Doulah MA, Simpson NAB, ReidJG, Rollason G, Dear PRF and Walker JJ. Academic Unit of Child Health and Obstetrics, University of Leeds, Leeds, Yorkshire

Introduction: Elevated maternal and fetal levels of TNF- $\alpha$ are associated with preterm delivery. A functional polymorphism which regulates production of TNF- is found within its promoter region. A previous study has demonstrated an association between maternal carriage of this high-secreting allele (TNF*2) and spontaneous preterm delivery.

Aim: To determine the association between fetal carriage of $\mathrm{TNF}^{\star} 2$ and preterm delivery following premature rupture of membranes (PTD-PROM).

Methods: 54 singleton babies who delivered $<32$ weeks following PROM were compared with 300 singletons delivered at term. The TNF- $\alpha-308$ geno- 
type was determined from neonatal blood spots using PCR-RFLP. Intergroup differences were determined using non-parametric analysis.

Results: The carrier frequency (TNF*2 heterozygotes + homozygotes) in these two groups was $43 \%$ versus $30 \%$ for the PTD-PROM and term groups respectively $\left(\chi^{2}=8.4 ; p=0.015\right)$. The $T^{2} F^{\star} 2$ allele frequency was 0.27 versus 0.17 respectively $\left(\chi^{2}=5.7 ; p=0.017\right)$. There was a stepwise increase in the frequency of PROM for each genotype (Figure 1).

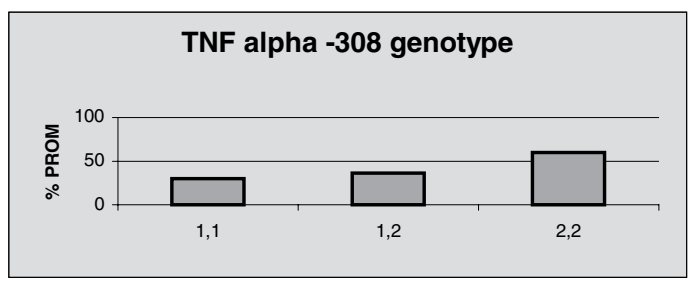

Conclusions: There is increased representation of the high-secreting TNF*2 allele in the preterm population who deliver following PROM. This preliminary study suggests that fetal carriage of this allele may result in excessive TNF- $\alpha$ production leading to PROM and subsequent preterm delivery.

\section{P26 RESPIRATORY SYNCITIAL VIRUS INFECTION IN AT RISK INFANTS AND THE POTENTIAL IMPACT OF PROPHYLAXIS}

Beresford MW ${ }^{\S}$, Clark $S J^{\star}$, Subhedar NV§ , Shaw $\mathrm{NJ}^{\S}$. Liverpool Women's Hospital $^{\S}$, University of Liverpool*

Background: A randomised controlled trial of intra-muscular humanised monoclonal antibody prophylaxis against respiratory syncitial virus (RSV) showed a $55 \%$ reduction in hospital admission rates in at risk infants.

Aims: To follow a cohort of at risk infants, to assess RSV infection rate and the potential impact of prophylaxis for a local health authority (LHA).

Methods: All infants who were born and resident at home within the LHA were eligible for this study. The at risk population was defined as infants who, at the beginning of the 1998/9 RSV season were: (1) under 6 months old and born prior to 36 weeks gestation, or (2) under 24 months of age and discharged home in supplemental oxygen. All infants from this cohort who were admitted with a respiratory diagnosis between October 1998 and March 1999 were identified. The cost of hospital admission (£1100) and an intensive care day (£1242) was obtained from the local hospital.

Results: 377 infants were identified as at risk, of whom 306 were group (1) and 80 were group (2). $28(7.4 \%)$ infants were admitted with bronchiolitis on 36 $(9.5 \%)$ occasions; 2 were admitted to the intensive care unit (ICU), one of whom died. 233 days were spent in hospital, of which 88 were ICU days. Median (interquartile range) age at admission and length of hospital stay was 4 (3-10) months and $2(2-5)$ days, respectively. RSV positivity was identified in $13(36 \%)$ admissions. However, assuming all 36 admissions were due to RSV, prophylaxis may have averted 20 admissions, saving £22,000. A further $£ 109,296$ may have been saved if this included both ICU admissions. The cost of treating our cohort for a full course of 5 injection could have ranged from $£ 799,240$ (if all infants weighed $<3.3 \mathrm{~kg}$ at the time of injection) to $£ 1,330,810$ (if all infants weighed $>3.3 \mathrm{~kg}$ and $<6.6 \mathrm{~kg}$ ).

Conclusions: Only $3.4 \%$ of this cohort developed proven RSV. Potential cost savings secondary to prophylaxis would, therefore, be an overestimate. Especially, as staffing and infrastructure costs could not be defrayed by a reduction in admissions. Careful consideration of risk factors is needed when selecting infants for RSV prophylaxis.

\section{P27 THE UNDERGRADUATE CORE CURRICULUM: TIME TO}

\section{PREACH WHAT WE PRACTICE?}

Erlewyn-Lajeunesse MDS and Hill CM. University Department of Child Health, Southampton General Hospital, Southampton SO16 6YD, UK

A core curriculum is fundamental to modern medical education. Undergraduate core curriculum development has taken place across the country on a school and departmental basis. Most have been independent efforts made by single institutions. This study is a collation of the undergraduate curriculum in Child Health from the medical schools in the United Kingdom and Republic of Ireland.

Method: All 28 University Departments were contacted by post with a request for their core curriculum in Child Health. The received data was then scrutinised and a collation made of the core syllabus items.

Results: 24 departments responded to the request for information (89\%). 23 stated that they have a core curriculum (82\%). 21 departments listed core knowledge whereas 16 listed skills and 8 their core attitudes. 717 different subject items were identified as being core. 223 items (31\%) were cited by only one department, a mere five received universal approval.

Discussion: There is a large variation in what is stated as being core. This may be due to differences in degree structure and curriculum development. It is not universally held that the standard of undergraduate teaching in Child Health should be that of the newly qualified doctor. However, as a pre-registration house officer, the new graduate is able to practice across the UK and may be involved with the care of children. We believe that there is a role for a national standard and that education could be improved by definition of a national core curriculum in Child Health. 


\section{PLENARY SESSION VII}

\section{P28 HUMAN GROWTH HORMONE THERAPY: POOR ADHERENCE EQUALS POOR GROWTH}

Hunter $I^{1}$, de Vries $C^{2}$, Morris $A^{3}$, MacDonald $T^{3}$, Greene $S^{1}$. Tayside Institute of Child Health ${ }^{1}$, Medicines Monitoring Unit ${ }^{2}$, Department of Medicine ${ }^{3}$ Ninewells Hospital and Medical School, Dundee, DD1 9SY

Background: Information on the adherence to prescribed growth hormone therapy $(\mathrm{hGH})$ has been gained previously from patient questionnaires, method with severe limitations. We had the unique opportunity to measure directly hGH prescription encashment using the Medicines Monitoring Unit (MEMO) database.

Setting and Subjects: All patients less than $18 \mathrm{yr}$. treated with hGH in Tayside region, Scotland.

Aim: To investigate the adherence of subjects to prescribed hGH therapy and relate this to growth during therapy.

Method: Encashed community prescriptions of hGH were measured and compared to the prescribed dose. An adherence index (days/annum) was then calculated. Height measurements were obtained from the patients record and ( SDS calculated (normal growth and Turner standard where appropriate).

Results: 42 patients' encashed 850 prescriptions for hGH during the study period. Adherence data was available on 39 (803 prescriptions); median age 9.5 yr. (range 0.6-16.9). Diagnostic breakdown was similar for national audit figures in Scotland. 33\% had an adherence index of less than 292 days/ annum, giving less than $80 \%$ of their correct dose. These were older: $12.7 \mathrm{yr}$ vs 8.4yr. $p<0.001$. Adherence was positively associated with ( height SDS $(r=0.51, p<0.001)$.

Conclusions: We present for the first time direct evidence of poor adherence to hGH therapy: One third of patients give less than $80 \%$ of their prescribed dose and this is directly associated with poor growth. Adherence of this level must to be taken into account when considering the response to therapy in both clinical practice and research studies.

\section{P29 WHAT IS ACHIEVED WITH CONVENTIONAL CORTISOL REPLACEMENT REGIMENS IN CHILDREN WITH CONGENITAL ADRENAL HYPERPLASIA (CAH)?}

Charmandari E, Hindmarsh PC, Lichtarowicz-Krynska EJ, Brook CGB and Aynsley-Green A. London Centre for Paediatric Endocrinology, The Middlesex and Great Ormond Street Hospitals, London, UK

Background: Little is known of how the plasma cortisol concentrations (PCC) achieved after stress replacement regimens in $\mathrm{CAH}$ relate to endogenous cortisol concentrations seen in normal children with severe stress.

Aim: To document the PCC after intravenous hydrocortisone administration in $\mathrm{CAH}$ patients and relate to $\mathrm{PCC}$ achieved by endogenous secretion in the stress of critical illness in previously normal children.

Methods: PCC were established, using 10 minute sampling intervals, in 20 $\mathrm{CAH}$ patients (age range: $6.25-16 \mathrm{yr}$, median age: $10.29 \mathrm{yr}$ ) following intravenous (iv) administration of hydrocortisone at a dose of $15 \mathrm{mg} / \mathrm{m}^{2}$. PCC were analysed in 60 critically ill mechanically ventilated children on admission to PICU and for 24 hours thereafter (age range: 0.25-16.3yr, median age: $2.5 \mathrm{yr}$ ). Exclusion criteria included illness duration $>24 \mathrm{~h}$, history of endocrinopathy or steroid administration.

Results: In the CAH patients, PCC reached a mean peak of $1567 \mathrm{nmol} / \mathrm{I}$ (SE 119.2) within 10 minutes of iv bolus, and fell rapidly thereafter remaining greater than $450 \mathrm{nmol} / \mathrm{l}$ for 2.5 hours only. In critically ill children the mean PCC on admission to PICU was $727 \mathrm{nmol} / \mathrm{l}$ (SE 52). $23 \%$ of patients had PCC $<450 \mathrm{nmol} / \mathrm{l}, 51 \%$ had PCC $450-1000 \mathrm{nmol} / \mathrm{l}$ and $26 \%$ had PCC $>1000 \mathrm{nmol} / \mathrm{l}$. PCC only fell gradually, mean level at $24 \mathrm{~h}$ being $515 \mathrm{nmol} /$ I (SE 53).

Conclusions: Mean peak PCC achieved after iv hydrocortisone bolus is considerably higher than mean PCC achieved from endogenous cortisol release in response to the acute stress of critical illness. There is a rapid fall in PCC within 2.5 hours after peak concentrations are achieved post bolus, whereas PCC in critically ill children remain elevated. The effect of PCC on suppression of precursors, eg. 17hydroxyprogesterone, in $\mathrm{CAH}$ and effect on immune function with the iv hydrocortisone bolus regimen should be addressed. These observations raise issues as to the optimal timing, dosage and frequency of administration of hydrocortisone replacement in emergency situations in patients with $\mathrm{CAH}$.

\section{P30 RESURGENCE OF PAEDIATRIC TB IN LONDON}

Atkinson $\mathrm{P}^{\star}$, Taylor $\mathrm{H}$, Maquire $\mathrm{H}^{\star}$, Sharland $\mathrm{M}$. CDSC Thames*, Paediatric Infectious Diseases Unit, St George's Hospital, London

Background: National rates of Tuberculosis in adults have steadily declined. However, in London there has been sustained increase in adult TB rates since 1987, which have been complicated by HIV/TB co-infection, and Multi Drug Resistant TB. No comparable data has previously been available for children.

Aim: to compare the trend in paediatric TB notifications in London over the same period.
Methods: Retrospective review of all case notifications by London boroughs to CDSC Thames from 1982 to 1998.

Results: London borough paediatric TB notifications fell to 1988. Since then notifications have increased from a nadir of 82 cases per annum in 1988 to a peak of 192 in 1998, an increase of $130 \%$. Notification rates varied between London boroughs from zero (Bromley/Havering/Richmond) to 58.4/100,000/ year (Westminster). The highest rates were seen in the 10-14 years age group, where rates for 10/32 (31\%) boroughs now reach WHO High Prevalence Status (>40/100,000/year).

Conclusions: Childhood TB in London is increasing in parallel to adult disease. Clinicians need to be aware of the increasing prevalence of this disease. Ensuring rapid contact tracing of all family members following the diagnosis of an infected adult is of critical importance. For many districts their current selective BCG policy may need reviewing. 